\title{
La Iglesia de Zaragoza durante el Trienio liberal. Espacio sagrado, opinión pública y legitimación del poder político
}

L'Église de Saragosse pendant le Triennat libéral. Espace sacré, opinion publique et légitimation du pouvoir politique

The Church of Zaragoza during the Liberal Triennium. Sacred space, public opinion and legitimization of political power

\section{Francisco Javier Ramón Solans}

\section{(2) OpenEdition}

\section{Journals}

Edición electrónica

URL: http://journals.openedition.org/bhce/2543

DOI: 10.4000/bhce. 2543

ISSN: 1968-3723

\section{Editor}

Presses Universitaires de Provence

\section{Edición impresa}

Fecha de publicación: 1 enero 2020

ISSN: 0987-4135

\section{Referencia electrónica}

Francisco Javier Ramón Solans, « La Iglesia de Zaragoza durante el Trienio liberal. Espacio sagrado, opinión pública y legitimación del poder político », Bulletin d'Histoire Contemporaine de l'Espagne [En línea], 54 | 2020, Publicado el 01 julio 2020, consultado el 30 diciembre 2020. URL : http:// journals.openedition.org/bhce/2543; DOI : https://doi.org/10.4000/bhce.2543

Este documento fue generado automáticamente el 30 diciembre 2020.

Bulletin d'histoire contemporaine de l'Espagne 


\title{
La Iglesia de Zaragoza durante el Trienio liberal. Espacio sagrado, opinión pública y legitimación del poder político ${ }^{1}$
}

\author{
L'Église de Saragosse pendant le Triennat libéral. Espace sacré, opinion publique \\ et légitimation du pouvoir politique \\ The Church of Zaragoza during the Liberal Triennium. Sacred space, public \\ opinion and legitimization of political power
}

Francisco Javier Ramón Solans

1 La matriz de la cultura política del primer liberalismo español es católica. No hace mucho tiempo esta tesis hubiera sido considerada por la historiografía como una afirmación paradójica e incluso extravagante. El relato mítico de la persecución religiosa, los discursos contrarrevolucionarios y las miradas retrospectivas de los liberales de finales de siglo alimentaron esta visión del carácter incompatible entre el liberalismo y el catolicismo ${ }^{2}$. La religión aparecía en el mejor de los casos como un instrumento de las nuevas élites liberales, una concesión de las autoridades para mantener contento al clero y lograr la estabilidad que permitiera poner en marcha en nuevo sistema constitucional.

2 Sin embargo, estas visiones sobre el papel de la Iglesia católica en el primer liberalismo se han visto drásticamente modificadas en las dos últimas décadas. Recientes investigaciones nos han ofrecido un panorama más rico y complejo de las relaciones entre religión y política durante el primer tercio del siglo XIX en España. La religión ya no sólo aparece como una barrera para el desarrollo del liberalismo sino como parte esencial de la cultura política de los diputados a Cádiz. Esto nos permite comprender mejor la definición tanto de ciudadanía como de nación en términos confesionales y que, en la línea del regalismo borbónico, la Iglesia católica fuera vista como un agente público, que podía contribuir a la difusión de valores políticos, morales y sociales. 
3 En esta línea de análisis, el presente artículo plantea la necesidad de abordar esta temática desde un punto de vista eclesiástico y local. El acento se ha puesto normalmente en la dimensión católica de los proyectos impulsados por los políticos liberales pero con frecuencia se ha descuidado el estudio de su puesta en marcha a nivel local y las reacciones de las élites eclesiásticas. En este sentido, el estudio del Cabildo metropolitano de Zaragoza durante el Trienio liberal adquiere una especial relevancia ya que permite iluminar nuevas facetas de la relación entre religión y política. Para ello, este artículo se servirá del estudio de la aparente contradicción existente entre las diferencias e inclusos los conflictos abiertos entre el Cabildo y las nuevas autoridades liberales y el hecho de que las dignidades catedralicias contribuyeran decisivamente a la puesta en marcha de los rituales constitucionales $\mathrm{y}$, por consiguiente, a la sacralización del nuevo orden político.

\section{Catolicismo, liberalismo e ilustración}

4 Frente a aquellas visiones dicotómicas que agrupaban a la Iglesia en el terreno de la reacción, desde hace algún tiempo se viene subrayando la pluralidad de posiciones en el seno del catolicismo español de finales del siglo XVIII y principios del siglo XIX. Con ello se ha tratado de superar la identificación entre catolicismo y reacción así como la equivalencia entre anti-ilustración y contrarrevolución ${ }^{3}$. Entre otros trabajos podríamos mencionar los pioneros estudios de Gérard Dufour que pusieron de relieve la existencia de sectores jansenistas, afrancesados y liberales dentro del clero español así como el importante papel que desempeñaron en el cambio de siglo. Con ello, estos estudios contribuyeron decisivamente a romper esa imagen monolítica de una reaccionaria Iglesia española ${ }^{4}$.

5 En la España de cambio de siglo, el catolicismo actuó pues como un repertorio cultural e intelectual tanto para defender una posición como la contraria. De esta manera, tanto la Ilustración como la anti-Ilustración y el liberalismo y el anti-liberalismo fueron esencialmente católicos. Este carácter confesional de los diversos programas culturales y políticos así como la dificultad que tienen ilustrados y liberales hispánicos para pensar la libertad de pensamiento y de cultos vendría según Javier Fernández Sebastián de la unidad confesional de los territorios de la monarquía hispánica frente a la pluralidad religiosa de otros territorios como Inglaterra, Holanda o Francia. Esto explica que en el mundo hispánico fuera muy difícil de concebir la religión y la política como dos esferas separadas ${ }^{5}$.

6 El estudio de las Cortes de Cádiz y la Constitución de 1812 sería uno de los campos más fértiles de estudio. No sólo una tercera parte de los diputados de las Cortes de Cádiz eran religiosos sino que los nuevos prohombres de la patria no concebían un régimen basado en la separación Iglesia y Estado porque simplemente no creían en ello. Así, lejos de cualquier manipulación o concesión de los liberales, nos encontramos con una elite política de formación clásica y católica que concebía la religión como parte integrante de su mundo ${ }^{6}$.

7 La Constitución de 1812 ejemplifica a la perfección esta simbiosis entre religión y política. La Carta Magna abría con una invocación que hacía referencia al «origen divino del orden esencial de la sociedad, y no al político que era en el que, desde su título, entraba a establecer la Constitución política sus principios» ${ }^{7}$. A través de esta formulación, se reconocía un principio legislativo anterior y superior a toda naturaleza 
humana ${ }^{8}$. Además, el artículo 12 de la Constitución gaditana declaraba que «la religión de la nación española es y será perpetuamente la católica, apostólica, romana, única y verdadera. La nación la protege por leyes sabias y justas, y prohíbe el ejercicio de cualquier otra». Tanto la intransigencia religiosa como la idea de protección se enmarcaban dentro de la tradición más regalista española y no se veían pues como incompatibles con el establecimiento de modernas libertades públicas.

El propio libro de la Constitución de 1812 adquiriría un carácter sagrado. Se convertiría en un símbolo casi mítico de la libertad política en España, especialmente tras la restauración absolutista. Además de las alegorías de la Minerva constitucional y de diversos monumentos y lápidas erigidos en su nombre, el propio libro adquiriría un papel central en la naciente ritualidad pública. Así, el ejemplar de la Constitución sería venerado públicamente, llevado en procesión, leído con solemnidad e incluso el propio hecho de abrirlo por primera vez vendría acompañado de salvas de artillería. Como señala Carlos Reyero, resulta difícil no ver reminiscencias religiosas en estas ceremonias ni paralelismos entre la Constitución y otros libros sagrados como el Corán o la Biblia9 . En este sentido, conviene recordar que en las sociedades semi-analfabetas, los textos estaban todavía investidos de poderes mágicos, de una sacralidad que nos recuerda la importancia y el poder de la palabra escrita ${ }^{10}$.

En el terreno de la ritualidad pública, tanto Juan Francisco Fuentes como Jordi Roca han subrayado cómo la fiesta liberal del Trienio es una fiesta híbrida, fundada sobre el ritual monárquico y la contribución de la Iglesia católica. Las celebraciones liberales en España serán pues diferentes de las fiestas revolucionarias francesas ya que en estas últimas se aprecia una progresiva descristianización de sus elementos festivos ${ }^{11}$. Así, durante el Trienio liberal, las iglesias de toda España se convirtieron en uno de los principales teatros de legitimación política con las misas, Te Deum y repiques de campanas que solemnizaron los grandes momentos del primer liberalismo español ${ }^{12}$.

La confesionalidad de la nación así como el papel reservado al catolicismo dentro del proyecto gaditano ha sido puesto en perspectiva a través de la historia comparada y la historia transnacional. Así, al analizarlo en el marco del ciclo revolucionario liberal mediterráneo de 1820 (Portugal, Nápoles y Grecia), las soluciones adoptadas por los liberales moderados y exaltados no parecen tan excepcionales ${ }^{13}$. Esta normalidad de la solución confesional se confirma todavía más al extender nuestra mirada más allá del Atlántico. Así, como señala Gregorio Alonso, tras las Independencias hispanoamericanas las nuevas repúblicas adoptaron la intolerancia religiosa, el patronato republicano y la identificación entre nación y religión, principios que sólo a partir de mediados del Ottocento comenzaron a cuestionarse abiertamente ${ }^{14}$.

\section{Entre espacio de oposición y espacio de poder}

11 La insurrección liberal del 5 de marzo de 1820 en Zaragoza comenzó con dos actos extremadamente simbólicos. Una parte de los amotinados se dirigió a la plaza real de Fernando VII para arrancar la lápida que llevaba su nombre y colocar en su lugar una placa dedicada a la Constitución. Este cambio adquiría una relevancia todavía mayor si tenemos en cuenta que este emplazamiento ya había sido objeto de una damnatio memoriae popular durante los motines de mayo de 1814, en los que se había arrancado la lápida de la Constitución, quemado varios ejemplares del código gaditano y colocado un busto del rey en la rebautizada plaza real ${ }^{15}$. Otra parte de los insurrectos se dirigió a 
la catedral de Zaragoza para solicitar «de la parte de la nación y de su excelencia» que se realizara un repique de campanas y se cantara un Te Deum por la publicación de la constitución. Esta petición ilustra a la perfección como desde sectores populares se interpretaba que todo cambio importante en la realidad política tenía que ser sancionado por el poder religioso para que pudiera subsistir y fuera legítimo ${ }^{16}$.

Este grupo armado fue recibido por el deán que se negó a mandar cantar un Te Deum, argumentando que no tenía la facultad para acceder a sus deseos ya que sólo el Cabildo lo podía ordenar. El deán les propuso ponerlo «en su noticia para su determinación como siempre se había practicado en iguales demandas de todas las autoridades». El interlocutor, cuyo nombre desconocía el deán, respondió airado que aquello era una desobediencia y que él mismo haría tocar las campanas de las torres de la basílica del Pilar y la catedral de la Seo. Así mientras continuaba la discusión entre el representante popular y el eclesiástico, se oyeron las campanas de ambas torres. El Cabildo aprobó lo ejecutado por el deán y «acordó esperar que se pidiese esta función en los términos correspondientes por alguna autoridad conocida $»^{17}$. Los argumentos no eran pues políticos sino de procedimiento. La Iglesia zaragozana había estado públicamente del lado del poder político de la ciudad en momentos tan convulsos como los Sitios o la ocupación francesa y quería continuar desempeñando su papel como centro legitimador del mismo ${ }^{18}$.

Finalmente, el 11 de marzo de 1820, las dignidades catedralicias recibieron la orden del capitán general de Aragón y destacado absolutista, el marqués de Lazán, quién también se había visto obligado a reconocer la nueva realidad constitucional. El Cabildo hizo sonar la campanas durante tres días en honor de la constitución y, por orden del Ayuntamiento de Zaragoza, mandó cantar un Te Deum el domingo 12 de marzo para agradecer a Dios que Fernando VII hubiera jurado la constitución de 1812. La ceremonia tuvo lugar en la basílica del Pilar y fue presidida por el arzobispo de Zaragoza, Manuel Vicente Martínez, que se había destacado por su neto compromiso por la causa absolutista ${ }^{19}$. El capitán general fue recibido por el Ayuntamiento, la Junta gubernativa y el Cabildo y acompañado hasta el lugar que le habían dispuesto debajo del altar mayor y la guarnición estaría colocada debajo del presbiterio. Tras la misa oficiada por el canónigo tesorero Joaquín Cornel, pronunció un discurso el profesor de derecho canónico, beneficiario de San Gil y destacado eclesiástico liberal, Miguel Laborda y Galindo $^{20}$. Capellán de la Milicia nacional, este último eclesiástico desempeñaría un papel central en la instalación y legitimación del régimen constitucional en Zaragoza, actuando como mediador entre el universo político y religioso.

La ceremonia revistió además especial importancia ya que a raíz de las tensiones experimentadas el 5 de marzo, el Cabildo decidió en pleno que «para cualquiera otra función que con el mismo objeto se pida con premura por las autoridades, pueda determinar el señor presidente sin necesidad de convocar a Cabildo si no se le ofrece alguna dificultad o inconveniente para ejecutarlo» ${ }^{21}$. Con ello se pretendían no sólo adaptarse a la velocidad de los nuevos tiempos históricos sino también evitar que en un futuro estas cuestiones de procedimiento pudieran generar conflictos con las autoridades políticas.

15 El juramento y la publicación de la constitución también mostraron la flexibilidad del Cabildo, que quedaba a la espera del día que decidieran las autoridades políticas y trasladaba por precaución la procesión a la Iglesia del Portillo que se celebraba el 25 de marzo con motivo de la Anunciación en caso de que el Ayuntamiento eligiera aquel 
día ${ }^{22}$. Finalmente, tal y como estaba previsto, el día 24 de marzo juraron la Constitución todos los racioneros, beneficiados, ministros y dignidades que componían las dos catedrales de la Seo y del Pilar. Este era un requisito previo para la gran ceremonia que se celebraría al día siguiente y en la que se leería y juraría la Constitución. Con ello, se ahorraban pues la conmoción que podría causar que un representante eclesiástico se negara públicamente a jurarla. En las misas celebradas por todo Zaragoza el 25 de marzo se leyó la Constitución tras el credo. Tras la misa se leía el juramento y se cantaba un Te Deum..$^{23}$ Como había ocurrido y ocurriría en otras tantas ocasiones la liturgia política se integraba perfectamente en la liturgia religiosa, contribuyendo así a la difusión de mensajes políticos hasta los rincones más apartados de la diócesis ${ }^{24}$.

\section{Entre el apoyo público y el disenso}

16 La colaboración del Cabildo en la sacralización del nuevo orden constitucional no quiere decir que existiera una plena adhesión a su causa. Así, como señala Pedro Rújula al hilo de estas ceremonias, «la unanimidad que manifestaban públicamente las distintas instancias del poder de la ciudad sólo era una actitud ante la evidencia de que la revolución se había impuesto de manera arrolladora» ${ }^{25}$. En Zaragoza, el período que va desde la revolución de marzo hasta las elecciones de julio va a ser particularmente crítico por la actividad propagandística reaccionaria ${ }^{26}$. Esta comenzaría cuando el ejército sofocó un motín contrarrevolucionario la noche del 14 de mayo de 1820, dejando dos muertos y cuarenta prisioneros ${ }^{27}$. Todo parecía señalar que había sido organizado por el marqués de Lazán, hermano de José Palafox, y Manuel Vicente Martínez, arzobispo de Zaragoza, que sufriría dos semanas de arresto domiciliario.

17 Antiguo obispo de Astorga, Manuel Vicente Martínez, había sido recompensado con el arzobispado de Zaragoza en 1816 por su compromiso contrarrevolucionario durante la Guerra de la Independencia. Se negó a jurar la constitución en repetidas ocasiones y sólo accedió después de que el rey la jurara el 10 de marzo de 1820. Durante el Trienio liberal, el arzobispo boicoteó de diversas maneras la instalación del régimen liberal y se inhibió de participar en los rituales que legitimaban el cambio político. Su ausencia era una forma de resistir y mostrar públicamente su hostilidad a las nuevas autoridades políticas. La actitud del arzobispo de Zaragoza supondría un auténtico rompecabezas para los autoridades liberales que temían los efectos negativos que podía causar no sólo la ausencia del prelado sino también cualquier declaración pública contra la constitución o las nuevas autoridades durante una ceremonia religiosa.

18 Como consecuencia del motín, el arzobispo de Zaragoza fue detenido en su propio palacio por orden del jefe político y liberal exaltado Luis Veyan, quién mandó establecer una guardia en cada una de sus puertas, impedir el acceso a los miembros del Cabildo y tapiar ventanas e incluso el alcantarillado. Este arresto domiciliario fue justificado por el jefe político por la tardanza con la que respondió a su carta del 14 de mayo en la que le informaba de los desórdenes y le pedía que excitara «a los zaragozanos al respeto debido a las autoridades y a la conservación de la tranquilidad pública, y ya para que pueda servirse dirigir su voz al clero del arzobispado, en el que no deja de haber alguna parte que coopera acaso por ignorancia, o por un celo mal entendido ${ }^{28}$. Si bien Veyan creía que el arzobispo estaba detrás del motín, no se atrevió a acusarlo formalmente y justificó su arresto domiciliario como una guardia de honor para proteger al arzobispo contra posibles ataques populares ${ }^{29}$. Estuviera o no 
involucrado el arzobispo, estas medidas le señalaban públicamente como uno de sus principales responsables.

19 La estrategia de Manuel Vicente Martínez durante su cautiverio ilustra a la perfección cómo desde los sectores eclesiásticos se integró desde un principio el nuevo lenguaje de los derechos constitucionales para defender sus posiciones. En su primera respuesta tras el arresto, Manuel Vicente se presentaba como un prelado juramentado, que había procurado siempre que el clero «no tomase parte directa ni indirectamente en los acontecimientos civiles y políticos» y que ignoraba que hubiera eclesiásticos en Aragón que no cooperaran en la consolidación del actual sistema de gobierno ${ }^{30}$. Al ver que no se le levantaba la "guardia de honor» pedía que si es un arresto «se me cite con arreglo a la constitución que tengo jurada los hechos o crímenes de que me haga cargo para el uso de mis derechos y el de mi libertad [...] y quien es el que me juzga criminalmente, y apoyado en que ley o autoridad vigente $»^{31}$. En las siguientes cartas, Manuel Vicente Martínez no sólo volvió a apelar a sus derechos constitucionales sino que también contactó a otras autoridades para saber si alguien había incoado algún proceso contra él.

Justo el día en el que el jefe político levantaba su arresto, el arzobispo dirigió un manifiesto a los zaragozanos ya que consideraba que su honor había sido vulnerado «tan atrozmente en la opinión pública» y entendía que «mi silencio pasaría entre algunos por una confesión del crimen». En este texto volvía a subrayar su colaboración con las autoridades, su autorización «a que el clero secular y regular de mi diócesis prestase el juramento» y su propio juramento de la Constitución una vez que lo había hecho el rey. Justificó su retraso a la hora de contestar el oficio del jefe político por haberlo recibido a las nueve de la noche, momento en el que era imposible predicar o llamar a los zaragozanos a conservar el honor. De nuevo, censuraba la guardia de honor por poner en duda «la confianza y amor de algunos zaragozanos» y, sobre todo, volvía sobre la violación de sus derechos constitucionales:

Soy tratado como reo; han pasado ya cinco días, y no se me recibe declaración, ni sé de que se me acusa, ni quien es mi delator, ni donde esta mi causa, ni quien es mi juez, ni cual será el fin de mis atropellamientos, ni ante qué potestad debo reclamar la protección de las leyes constitucionales tan escandalosamente infringidas en mi persona. ${ }^{32}$

21 El Cabildo solicitó explicaciones al jefe político por la detención del prelado. Luis Veyan trataba de tranquilizar al Cabildo, diciendo que se trataba tan sólo de «una guardia de honor para la seguridad del prelado, a causa de los rumores esparcidos de haber tenido parte en la desagradable ocurrencia de la noche del 14 de cuya falsedad estaba persuadido». De nuevo, Veyan delegaba responsabilidades y señalaba «que la guardia de arresto había sido dictada por el Ayuntamiento y que a virtud de oficio de este se hallaba pendiente causa del prelado en la comisión militar» ${ }^{33}$.

Ante esta situación el Cabildo decidió organizar rogativas en ambos templos para que la divina providencia se dignase declarar y conservar la inocencia y buen nombre del prelado, gesto que el arzobispo agradeció vivamente ${ }^{34}$. Poco después de esta detención, una de las dignidades del Cabildo, el arcediano de Daroca, Juan Francisco Martínez y Castrillón fue confinado en el convento de los agustinos descalzos en virtud del decreto que ordenaba recluir a los signatarios del manifiesto de los Persas. Durante la Guerra de la Independencia Martínez y Castillón no sólo se había mostrado un claro partidario del regreso al absolutismo sino que también se había visto detenido junto con otros 
eclesiásticos por la aparición de un cartel que decía «mierda para Francia» en una de las paredes de la catedral de la Seo el 2 de junio de 1810, en los prolegómenos de las fiestas por la toma de Lérida y Mequinenza ${ }^{35}$. Por su compromiso absolutista, Martínez y Castillón sería recompensado después del Trienio con el obispado de Palencia. La situación se volvió crítica para el alto clero de la ciudad cuando la polémica llegó a los medios. El periódico liberal-progresista madrileño El Constitucional publicó una carta en la que informaba de la detención del arzobispo y otros eclesiásticos ${ }^{36}$. En una segunda carta anónima, aparecida en el número siguiente y titulada «Reflexiones sobre los acontecimientos de Zaragoza», el autor se mostraba muy crítico con la Iglesia, cualquiera que haya comparado su viciosa organización, sus inmensas riquezas, su espíritu generalmente ultramontano, con la sencillez de la antigua disciplina, con la pobreza de los primeros ministros, con las doctrinas sanas y verdaderamente ortodoxas, ha debido prever que aquella numerosa corporación opondría siempre la más tenaz resistencia a una regeneración completa del cuerpo social. Además, el artículo llegaba a acusar de traición al clero zaragozano, señalando que está no era sino la punta del iceberg de futuras rebeliones eclesiásticas contra el orden constitucional:

El arzobispo y los canónigos de Zaragoza, más valientes que la multitud de eclesiásticos enemigos secretos de la Constitución, han formado un plan inicuo y sangriento, tan contrario a la mansedumbre de la Religión que deben profesar, como a la tranquilidad del Estado, a cuyas leyes deben someterse ${ }^{37}$.

Exasperados por esta polémica, los canónigos discutieron cuál era la mejor manera de responder a estos ataques. Con el objetivo de mejorar su imagen participaron de una suscripción voluntaria a favor de la Milicia local con 3.000 reales de vellón, señalando «que no le permiten extenderse más en este caso como lo haría gustoso estimulado del acendrado patriotismo que tan acreditado tiene en cuantas ocasiones se le han ofrecido». Esta primera iniciativa para mejorar su imagen tuvo un efecto inmediato y el Jefe político agradecía la «generosidad y patriotismo» de dicha institución ${ }^{38}$.

A las dignidades del Cabildo les preocupaba especialmente los efectos negativos que podía tener el artículo de El Constitucional si «lo tolerase con su silencio y no lo refutase a lo menos en el tribunal de la pública opinión acordó hacerlo desde luego por medio de un manifiesto que al paso acreditase la falsedad de lo referido» además obviamente de denunciarlo en los tribunales de justicia ${ }^{39}$. El uso de esta imagen de la opinión pública como un tribunal de apelación comenzó a gozar de gran popularidad gracias a la extraordinaria campaña desarrollada por los medios jansenistas franceses y especialmente por la revista Nouvelles ecclésiastiques para combatir la aplicación de la bula Unigenitus en Francia durante la primera mitad del siglo XVIII. Desde las polémicas religiosas su uso se generalizaría a otros aspectos de la sociedad, desempeñando un papel clave en la Revolución francesa y en el surgimiento de una esfera pública moderna ${ }^{40}$. En España, su uso cristalizó precisamente durante las coyunturas revolucionarias de 1808-1814 y 1820-1823 con un marcado carácter liberal ${ }^{41}$. En este sentido, resulta interesante observar como el Cabildo zaragozano vuelve precisamente sobre este término de origen religioso para combatir a sus enemigos en el espacio en el que se veía más desafiada: la esfera pública. 

argumentaba que había publicado la carta contra el Cabildo por

la facilidad en creer implicados a varios individuos del alto clero en una conspiración contra la libertad. Desde que esta nació en España, el alto clero de la ciudad que fue su cuna, se declaró abiertamente en contra, y cuando hubo visto su ruina se envaneció con el título de su perseguidor; así lo dio a entender al público por el órgano elocuente de su dignísimo abogado: al alto clero se han confiado en los años que acaban de pasar las persecución que han llenado los calabozos de víctimas [...]. Harto lo han deplorado otros muchos individuos del alto clero, llenos de virtudes y de ilustración, justamente afligidos de tanto escándalo y de tanta perversidad ${ }^{44}$.

Lo cierto es que a José Joaquín Mora no le faltaba razón ya que además de la actitud del arzobispo de Zaragoza, podía censurar que tres de los siete firmantes aragoneses del manifiesto de los Persas (1814) eran eclesiásticos. Además del ya mencionado arcediano de Daroca (miembro del Cabildo zaragozano) estaba el cura de Hortaleza y el canónigo 
de Huesca Gerónimo Castillón. Estos dos últimos habían sido recompensados durante la restauración absolutista con el decanato de la catedral de Córdoba y el obispado de Tarazona, respectivamente ${ }^{45}$.

Además, lejos de ser desmentida, esta imagen contrarrevolucionaria de la jerarquía eclesiástica zaragozana se vio confirmada públicamente con el descubrimiento de un complot el 30 de diciembre de 1820 en el que fueron arrestados el deán Benito Fernández Navarrete y el canónigo Joaquín Cistué. Al parecer tanto estos eclesiásticos como el canónigo de Huesca Tomás Castillo Larroy, el brigadier Diego de la Vega y el maestro sastre Martín Moreno habían participado en reuniones conspirativas en la casa de la marquesa de Lazán el 23 y 24 de diciembre y en la casa del canónigo Cistué el 26 de diciembre para atentar contra el gobierno, quitar las autoridades y asesinar a liberales ${ }^{46}$.

33 Aunque el 3 de enero de 1821 el juez de primera instancia Mariano Dutú había señalado ya las contradicciones en las declaraciones del denunciante el aceitero Manuel Salillas y en su careo con los acusados, estos no serían liberados hasta el 9 de enero, probablemente con el objetivo de que no empañarán la entrada triunfal del nuevo capitán general Rafael de Riego el 8 de enero. Este momento supondría el punto álgido de la tensión entre autoridades religiosas y políticas ya que Riego no sería recibido por ninguna autoridad religiosa durante su entrada triunfal en Zaragoza. Ni siquiera fue recibido por las autoridades religiosas durante su visita privada al Pilar ${ }^{47}$. Al día siguiente, el arzobispo y el Cabildo le visitaron y le ofrecieron como regalo pensionar diez huérfanas de la casa de la misericordia en recuerdo de su entrada triunfal a Zaragoza ${ }^{48}$.

34 La liberación de los prisioneros el 9 de enero se convirtió en una demostración del apoyo popular tanto a la marquesa de Lazán como a los eclesiásticos involucrados. Primero fueron liberados el deán y los canónigos, que se dirigieron a la basílica del Pilar para agradecer a la virgen su libertad. Poco después era liberada la marquesa de Lazán, que sería recibida en una plaza de San Antón repleta de gente. Se tiraron al aire palomas con cintas en las que decían «Viva la inocencia». Desde la prisión fue llevada hasta la basílica del Pilar en el coche de su sobrino el Conde de Sobradiel. En el trayecto se dieron vivas a la constitución y la inocencia y se arrojaron al aire sombreros en señal de alegría. En la catedral, el deán permitió a la marquesa acceder a adorar a la imagen dentro del rejado. Tras una breve oración, la marquesa de Lazán gritó ante el público que la rodeaba «viva la Virgen del Pilar que protege la inocencia». Por la tarde, Riego visitaría a la marquesa de Lazán en su domicilio y asistiría a la función de teatro realizada en su honor, tratando con ello de cerrar las heridas que su nombramiento como capitán general hubieran podido causar ${ }^{49}$.

Durante su estancia en la capital aragonesa, Riego evitaría asistir a festejos en las dos catedrales, incluso en ceremonias tan importantes como San Valero o la bendición de las candelas. Así, por ejemplo para la misa de domingo, prefirió asistir a las iglesias de San Ildefonso, San Felipe o Santa Cruz. Lejos de las dignidades eclesiásticas y el arzobispo, con el concurso de la tropa y los discursos del catedrático de la universidad de Zaragoza y beneficiario de San Gil, Miguel Laborda y Galindo, Rafael de Riego se sentiría mucho más cómodo. De esta manera, aunque las tensiones entre autoridades siguieron, la agitación contrarrevolucionaria en la capital aragonesa se cerraría prácticamente con la campaña propagandística para la destitución de Rafael de Riego, 
en la que se le acusaba entre otras cosas de dirigir una conspiración republicana que, con apoyo de un ejército ruso, venía para quemar el Pilar ${ }^{50}$.

Por otro lado, el Cabildo no era una entidad homogénea políticamente. Así, entre sus miembros estaría por ejemplo el canónigo José Antonio Marco, canónigo doctoral de Zaragoza y miembro de la junta provisional de gobierno, que sería uno de los encargados junto con Valentín Solanot de preparar un documento destinado a un público muy amplio sobre las bondades de la constitución ${ }^{51}$. El documento reservaba un papel fundamental al clero en su difusión, instruyendo «a los sencillos, haciéndoles conocer la justicia, la razón, la conveniencia pública, la piedad religiosa de que están llenas las páginas venerables de la Constitución $»^{52}$. Además se enfatizaba que dicho texto «protege enérgica y decisivamente la sagrada religión de Jesucristo» y que «será tratado como traidor y condenado a muerte, el que de hecho atentase contra esta inmaculada hija del cielo» ${ }^{53}$. Explicadas estas bondades, se señalaba Considerad ahora, pueblos sencillos, cuan exquisita maldad es la de aquellos, que por sus miras interesadas tratan de alucinaros para haceros sospechosa la Constitución, diciéndoos que ella no protege nuestra Religión, cuando ella es precisamente uno de sus más firmes apoyos, como ya lo han dicho sabiamente muchos venerables prelados de la Iglesia $^{54}$.

\section{Espacios de legitimación política}

La religión era uno de los pilares sobre los que se levantaba el nuevo orden constitucional y por tanto, los discursos que trataban de presentar al régimen liberal como anti-religioso causaban pavor entre las nuevas autoridades. Por parte de la Iglesia católica, aún cuando las dignidades capitulares fueran mayoritariamente contrarias a la Constitución, primaban sus intereses corporativos: el Cabildo quería seguir siendo el centro de legitimación de la política y se esforzaba por concurrir a los rituales públicos a los que eran invitados.

Así, si bien las desavenencias entre una parte notable del alto clero zaragozano y el nuevo régimen eran manifiestas, esto no impidió su colaboración con el poder. La Constitución de 1812 reservaba a la Iglesia católica un rol muy importante en el proceso electoral. Según los artículos 47 y 58, el cura párroco debía celebrar una misa solemne de Espíritu Santo antes de las votaciones y, una vez terminadas, debía cantar un Te Deum. En el marco de las elecciones a Cortes, el Cabildo participó en la primera votación, aquella a nivel parroquial. Conforme a la orden del Capitán general, el 28 de marzo de 1820, las catedrales de la Seo y el Pilar echaron las campanas al vuelo por la llegada de la convocatoria de Cortes. En el marco de las elecciones, el Cabildo participó en la primera votación, a nivel parroquial. En primer lugar y conforme a los deseos del Ayuntamiento de Zaragoza, anunciaron las elecciones con sermones de los canónigos Oliver y Bartra en las catedrales de la Seo y el Pilar respectivamente. Las votaciones tuvieron lugar la tarde del 30 de abril con misa y Te Deum del deán de la catedral. A cada paso, el proceso electoral fue sacralizado por las dignidades del Cabildo hasta la propia instalación de las Cortes que sería celebrada con repique de campanas durante tres días consecutivos y misa solemne con Te Deum ${ }^{55}$.

La Iglesia zaragozana contribuyó también a solemnizar la lectura liberal del recuerdo a la Guerra de la Independencia. Así, celebraron desde 1821 aniversarios solemnes por las víctimas del levantamiento del 2 de mayo de 1808 en Madrid, por todos los muertos de 
la Guerra de la Independencia el 1 de junio así como por la instalación de las Cortes extraordinarias en Cádiz en septiembre de $1810^{56}$. Rafael de Riego mandó conmemorar el levantamiento del 5 de marzo de 1820 con una misa y un Te Deum para agradecer a Dios «por los favores que dispensa a nuestro pueblo» había obtenido desde entonces. La ceremonia tuvo lugar en la basílica de Nuestra Señora del Pilar. Las actas capitulares muestran como el Cabildo estaba muy preocupado por agradar al capitán general y acordaron que «la solemnidad y adornos sean como en las primeras clases» ${ }^{57}$. El cronista local Faustino Casamayor señala que la ceremonia se realizó «con la mayor magnificencia» a expensas de un Cabildo que «quiso dar esta nueva prueba de sus buenos deseos» ${ }^{58}$.

40 Casi como una réplica simbólica del levantamiento del 5 de marzo, la tropa marchó con banderas y música desde la rebautizada plaza de la Constitución hasta la plaza del Pilar, donde fueron recibidos con toda solemnidad. La misa fue celebrada por el canónigo Gregorio Peña y el sermón quedó a cargo del capuchino liberal Manuel Antorán, que predicó a favor de la Constitución. Todos los altares estaban iluminados, la Santa Capilla decorada como los grandes días y el Te Deum fue cantado «con toda la música» 59 .

\section{Conclusión}

Los acontecimientos que llevaron a la restauración del absolutismo en 1823 fueron celebrados en Zaragoza con Te Deum y repique de campanas. Si bien con toda probabilidad el entusiasmo de la jerarquía eclesiástica fue mayor, lo cierto es que el aparato ritual no disto mucho de lo visto durante el Trienio. Como un reflejo de la fiesta liberal, la fiesta absolutista también conmemoró su propia visión del pasado, celebrando cada primero de junio desde 1823, un aniversario por aquellos que fallecieron "defendiendo la Religión y el Trono, con las armas en la mano» y en «desagravio de la impiedad irreligión y desordenes que se han cometido desde el año 1808 y en memoria de la libertad del rey» ${ }^{60}$. Al igual que las milicias nacionales, los voluntarios realistas participaron en las ceremonias religiosas que se produjeron en las dos catedrales.

Incluso el Cabildo de Zaragoza realizó algunas concesiones especiales en honor de las tropas francesas que habían «liberado la ciudad», permitiéndoles celebrar misas especiales los domingos y el santo de su monarca ${ }^{61}$. El historiador francés Grandmaison destacaba la especial y calurosa acogida que recibieron las tropas francesas, recepción que todavía era más impactante al compararla con la que los zaragozanos les dispensaron en 1808:

La lección parecía más impactante todavía el 26 de abril, cuando nuestras tropas entraron, batiendo tambores, banderas al viento, en Zaragoza. Las campanas y relojes de Nuestra Señora del Pilar sonaban con toda su fuerza en honor de aquellos contra quiénes, menos de quince años antes, los aragoneses había sostenido dos sitios encarnizados ${ }^{62}$.

Sin embargo, el historiador francés olvidaba que durante la ocupación francesa de Zaragoza y la breve puesta en marcha del sistema liberal en 1813, las campanas de la basílica del Pilar también festejaron las victorias de Napoleón y la Constitución de $1812^{63}$. De hecho, es precisamente a raíz del juramento a la Constitución durante el 
Trienio liberal que uno de los más lucidos analistas del fascinante alumbramiento del siglo XIX, François-René de Chateaubriand, decía:

Todos los pueblos, impresionados por la movilidad de las cosas humanas, han buscado un punto de apoyo fuera del mundo para estabilizar sus instituciones; todos, ya sean realistas o republicanos, se han apoyado sobre el altar; todos se han apresurado a denominar sus principios como sagrados ${ }^{64}$.

En la España del primer tercio del siglo XIX, las diversas culturas políticas no sólo buscaron legitimarse a través de la religión y sus rituales públicos sino que también querían convertir a la Iglesia un agente del estado clave para difundir mensajes políticos y educar a la población. No hay pues ninguna contradicción entre la importancia atribuida al catolicismo en la legitimación del liberalismo y la puesta en marcha de la legislación desarrollada por las Cortes. Con una cultura católica, los diputados no buscaban neutralizar la presencia de la Iglesia católica en el espacio público sino reformarla para adaptarla al nuevo sistema constitucional y convertirla en un instrumento del estado para legitimar su acción, educar y moralizar a los ciudadanos y difundir su discurso político hasta los rincones más apartados de España.

La actitud del bajo y alto clero ante la instalación de este nuevo sistema constitucional no fue unívoca. Algunos eclesiásticos se comprometieron de manera entusiasta con este nuevo proyecto político y participaron activamente en su configuración como diputados a Cortes. Así, mientras algunos vieron en el nuevo régimen liberal la forma de lograr la tan ansiada reforma de la Iglesia española, otros rechazaban parcial o totalmente el régimen constitucional y especialmente las medidas que afectaban a la reforma de la Iglesia como la supresión de la Inquisición y de la Compañía de Jesús, la ley de monacales que suprimía unos 800 monasterios y conventos cuyo número era inferior a 24 o la expulsión del nuncio y la ruptura de relaciones diplomáticas con Roma.

En Zaragoza el arzobispo y una parte de las dignidades del Cabildo zaragozano se opusieron al nuevo régimen político y estuvieron muy probablemente vinculados con actividades conspirativas para derribarlo. A pesar de estas simpatías con la causa contrarrevolucionaria, ni el arzobispo ni el Cabildo querían aparecer ante los zaragozanos como instituciones que instigaban la rebeldía frente a la autoridad pública. Esta preocupación les llevó a invocar al «tribunal de la opinión pública» a través de manifiestos y artículos en prensa así como, en el caso del arzobispo, a apelar a los derechos constitucionales. Aunque fuera para combatir presupuestos liberales, lo cierto es que esta reacción eclesiástica es una buena muestra de la extraordinaria capacidad de adaptación de la Iglesia católica a los nuevos tiempos, siendo capaz de integrar rápidamente entre sus estrategias nociones tan modernas como la existencia de una esfera pública y el uso de los derechos constitucionales como argumento político.

Independientemente de su compromiso con una u otra causa, la jerarquía eclesiástica zaragozana, con la excepción del arzobispo, contribuyeron activamente al desarrollo de las festividades liberales durante el Trienio. Para el Cabildo era una ocasión perfecta para mostrar su fidelidad política, reconciliarse con el nuevo régimen y mejorar su imagen pública tras las detenciones de diversos de sus miembros y las numerosas polémicas en los medios. Colaborar con las autoridades públicas en la ritualidad pública era para ellos algo natural, una parte fundamental de su misión en la sociedad. Paradójicamente, el hecho de negarse a tomar parte de la fiesta liberal hubiera 
contribuido al proceso de secularización de un espacio tan querido por la Iglesia como el de la legitimación política.

\section{NOTAS}

1. Este trabajo ha contado con la financiación del proyecto de investigación MINECO HAR2015-65991-P Entre revolución y contrarrevolución. Ciudades, espacio público, opinión y politización (1789-1888) (Universidad de Zaragoza) y del Grupo de investigación de referencia del Gobierno de Aragón H02-17R Politización, políticas del pasado e historiografia en Aragón y la España contemporánea (Universidad de Zaragoza). 2. El estudio del papel de la Iglesia en la Revolución francesa, también se vería mediado por similares consideraciones. Ver Dale Van Kley, Los orígenes religiosos de la Revolución francesa. De Calvino a la constitución civil (1560-1791), Madrid, Encuentro, 2002.

3. Andoni Artola Renedo y Antonio Juan Calvo Maturana, «Declinaciones de la reacción eclesiástica contra la Revolución francesa en España (1789-1808)», Hispania, nº 256, 2017, p. 437-469.

4. Entre su ingente obra se podrían mencionar sus trabajos sobre el eclesiástico Juan Antonio Llorente. Gérard Dufour, Juan Antonio Llorente en France (1813-1822). Contribution à l'étude du Libéralisme chrétien en France et en Espagne au début du XIXe siècle, Ginebra, Droz, 1982 y Juan Antonio Llorente. El factótum del rey intruso, Zaragoza, Prensas de la Universidad de Zaragoza, 2014.

5. Javier Fernández Sebastián, «Toleration and freedom of expression in the Hispanic World between Enlightenment and Liberalism», Past \& Present, no 211, 2011, p. 159-197. 6. Emilio La Parra López, El primer liberalismo español y la Iglesia. Las Cortes de Cádiz, Alicante, Instituto de Estudios Juan-Gil Albert, 1985, pp. 35-65. Para la presencia de eclesiásticos en las Cortes de Cádiz ver Manuel Pérez Ledesma, «Las Cortes de Cádiz y la sociedad española», en Miguel Artola (ed.), Las Cortes de Cádiz, Madrid, Marcial Pons, 2003, p. 167-206 y 172.

7. José María Portillo Valdés, Revolución de nación. Orígenes de la cultura constitucional en España, 1780-1812, Madrid, Centro de Estudios Políticos y Constitucionales, 2000, p. 319 y para un análisis de la nación católica ver pp. 259-491. Para la ciudadanía católica y la influencia de la religión en el primer liberalismo véase asimismo Gregorio Alonso, La nación en capilla. Ciudadanía católica y cuestión religiosa en España, 1793-1974, Granada, Comares, 2014.

8. José María Portillo Valdés, Revolución de nación..., op.cit., p. 451.

9. Carlos Reyero, Alegoría, nación y libertad. El Olimpo constitucional de 1812, Madrid, Siglo XXI, 2010, pp. 65-112.

10. Martyn Lyons, The Writing Culture of Ordinary People in Europe, C. 1860-1920, Cambridge, Cambridge University Press, 2013, p. 3.

11. Juan Francisco Fuentes, «La fiesta revolucionaria en el trienio liberal español (1820-1823)», Historia social, n 78, 2014, p. 43-59 y Jordi Roca Vernet, «Fiestas cívicas en la Revolución Liberal: entusiasmo y popularidad del régimen», Historia social, $\mathrm{n}^{\mathrm{o}} 86$, 2016, pp. 71-90. 
12. No debemos ver en la importancia de la religión en estas festividades un símbolo de la debilidad del poder político, como señala Jean-René Aymes, sino como un eje vertebral del proyecto nacional del liberalismo español. Jean René Aymes, «Las fiestas religiosas y profanas en la época romántica como indicadores de opiniones ideológicas y de mentalidades (1833-1868)», en Juan Francisco Fuentes y Lluís Roura (eds.), Sociabilidad y liberalismo en la España del siglo XIX. Homenaje a Alberto Gil Novales, Lérida, Milenio, 2001, p. 183-205.

13. Maurizio Isabella, «Citizens or Faithful? Religion and the Liberal Revolutions of the 1820s in Southern Europe», Modern Intellectual History, $\mathrm{n}^{\circ}$ 12, 2015, p. 555-578

14. Gregorio Alonso, «A Transatlantic Loyalty in the Age of Independence: Catholicism and Nation Building in Spain and Latin America», en Paul Garner y Angel Smith (eds.), Nationalism and Transnationalism in Spain and Latin America, 1808-1923, Cardiff, University of Wales Press, 2017, p. 45-67.

15. Francisco Javier Maestrojuán Catalán, Ciudad de vasallos, Nación de héroes. Zaragoza: 1809-1814, Zaragoza, Institución «Fernando el Católico», 2003, p. 490-493.

16. Archivo del Cabildo metropolitano de Zaragoza, Libro de actas del Cabildo metropolitano de Zaragoza (en adelante LACMZ), 5.03.1820, fol. 39.

17. Ibidem, fols. 39-40.

18. Para las vicisitudes del Cabildo durante la Guerra de la Independencia, véase Francisco Javier Ramón Solans, La Virgen del Pilar dice... Usos políticos y nacionales de un culto mariano en la España contemporánea, Zaragoza, Prensas de la Universidad de Zaragoza, 2014, p. 79-129.

19. Manuel Vicente Martínez y Giménez [Tartanedo, Guadalajara, 5.10.1759-Zaragoza, 9.02.1823]. Catedrático de filosofía y teología del colegio universitario de Sigüenza así como canónigo penitenciario de su catedral. Antes de tomar posesión de la diócesis de Zaragoza, fue canónigo magistral de la catedral de Murcia, obispo de Astorga y arzobispo electo de Granada. Este prelado era uno de esos setenta obispos fieles a la monarquía absoluta que habían sido nombrados entre 1814 y 1820 para cubrir las vacantes provocadas por la Guerra de la Independencia. José Blasco Ijazo, Obispos y arzobispos que han regido la diócesis de Zaragoza, Zaragoza, Talleres Editoriales Librería General, 1959, p. 55 y William J. Callahan, Iglesia, poder y sociedad en España, 1750-1874, Madrid, Nerea, 1989, p. 114.

20. Miguel Laborda y Galindo (Zaragoza, 19.07.1781-¿1858?). Miembro de la Real Academia de jurisprudencia práctica de Zaragoza, se decantó por la carrera eclesiástico. En 1816 fue nombrado beneficiado de San Gil Abad en Zaragoza. Durante el trienio liberal, pronunció numerosas oraciones en apoyo del proceso revolucionario. Asimismo, fue fiscal eclesiástico castrense y capellán de la Milicia Nacional Voluntaria de infantería. Tras la década ominosa, mostró su compromiso con la causa de la reina Isabel, apareciendo como miembro de la Junta Provisional instalada en Zaragoza y se mostró partidario de la supresión de conventos y la libertad de imprenta. Como premio por su compromiso fue nombrado obispo de la diócesis vacante de Puerto Rico (cargo que no llegó a desempeñar) y senador del reino en 1837. Miguel Laborda obtuvo una canonjía y, más en la catedral de Toledo, llegando a ser nombrado en 1852 maestrescuela y caballero comendador de Carlos III. Francisco Javier Ramón Solans, «Laborda y Galindo, Miguel», en Diccionario biográfico de parlamentarios españoles. 1820-1854, Madrid, Cortes Generales, 2012 (edición digital (ISBN- 978-84-7943-429-8).

21. LACMZ, 11.03.1820, fol. 46.

22. LACMZ, 16.03.1820, fol. 50.

23. Faustino Casamayor, Años políticos e históricos de las cosas más particulares en la Imperial, Augusta y Siempre Heroica ciudad de Zaragoza. [Manuscrito que se encuentra en la Biblioteca Universitaria de Zaragoza], tomo 37, 24 y 25 de marzo de 1820, fols. 57-59. 
24. Ver para el caso francés Vincent Petit, «Pro Deo et Patria. Prier pour l'État en France au XIX siècle», Amnis, $\mathrm{n}^{\circ}$ 11, 2012, mis en ligne le 10 septembre 2012, consulté le 11 mai 2018. URL : http://journals.openedition.org/amnis/1668.

25. Pedro Rújula, Constitución o muerte: el trienio liberal y los levantamientos realistas en Aragón (1820-1823), Zaragoza, Rolde, 2000, p. 29

26. Pedro Rújula, Constitución... op.cit., p. 45.

27. Ibídem, p. 34-59.

28. Manuel Vicente Martínez, Las vejaciones y atropellamientos que he sufrido en mi persona por espacio de cinco días consecutivos, Zaragoza, Imprenta de Andrés Sebastián, 1820, s.p.

29. Ibídem. El manifiesto aparecería mencionado en diversos medios, entre ellos en Miscelánea de Comercio, Política y Literatura, 2 de junio de 1820.

30. Anexo 3 en Manuel Vicente Martínez, Las vejaciones, op.cit.

31. Anexo 4 en Ibídem.

32. Manifiesto del 19 de mayo de 1820 en Ibídem. El jefe político se sintió obligado a responder a las acusaciones del arzobispo y publicó un manifiesto en que descargaba la responsabilidad de la detención en el Ayuntamiento de la capital y en un miliciano que había visto al arzobispo mantener reuniones sospechosas con los monjes de la Cartuja de la Concepción. Miscelánea de comercio, política y literatura, 5 de junio de 1820.

33. LACMZ, 19.05.1820, fol. 76.

34. LACMZ, 31.05.1820, fol. 80

35. Faustino Casamayor, op.cit., tomo 27, 2 de junio de 1810 y 4 de junio de 1810, fol. 37 .

36. El Constitucional, 20 de mayo de 1820.

37. El Constitucional, 22 de mayo de 1820.

38. LACMZ, 31.05.1820, fol. 79.

39. LACMZ, 10.06.1820, fol. 89-90.

40. Keith Michael Baker «L'opinion publique comme invention politique», en Au tribunal de l'opinion. Essais sur l'imaginaire politique au XVIII siècle, París, Payot, 1992. pp. 219-265. Para los orígenes religiosos, ver Catherine Maire, «Les jansénistes et le millénarisme. Du refus à la conversion», Annales. Histoire, Sciences Sociales, no 63-1, 2008, p. 7-36 y 14-15 e id., Les convulsionnaires de Saint-Médard. Miracles, convulsions et prophéties à Paris au XVIII siècle, París, Gallimard, 1985, p. 33

41. Javier Fernández Sebastián, «From the 'Voice of the People' to the Freedom of the Press: The Birth of Public Opinion in Spain», en Jesús Astigarraga (ed.), The Spanish Enlightenment Revisited, Oxford, Voltaire Foundation, 2015, p. 213-233

42. El Constitucional, 6 de junio de 1820.

43. Ibídem.

44. Ibídem.

45. Pedro Rújula López y Javier Ramón Solans, «Representantes y representación: los diputados aragoneses en las Cortes de Cádiz», Trienio: Ilustración y liberalismo, nº 61, 2013, p. 7-28

46. LACMZ, 19.01.1821, fol. 1-5.

47. Faustino Casamayor, op.cit., tomo 38, 8 de enero de 1821, fol. 14.

48. Faustino Casamayor, op.cit., tomo 38, 9 de enero de 1821, fols. 15-21 y LACMZ, 1-02.1821, fol. 20.

49. Faustino Casamayor, op.cit., tomo 38, 9 de enero de 1821, fols. 15-21 y Miscelánea de Comercio, Política y Literatura, 13 de enero de 1821.

50. Pedro Rújula, Constitución... op.cit., p. 66-68 y para la inestabilidad provocada por el affaire Riego ver Pedro Rújula, Contrarrevolución. Realismo y Carlismo en Aragón y el 
Maestrazgo, 1820-1840, Zaragoza, Prensas de la Universidad de Zaragoza, 1998, p. 65-66 y 70. A partir de ese momento, la actividad contrarrevolucionaria al margen de excepciones como la insurrección de diciembre de 1821 de Huesca se centrará fundamentalmente en las zonas rurales sobre todo en el Bajo Aragón y en distintos puntos de Aragón hasta la oleada insurreccional de Julio. Para la noticia del Pilar ver Alberto Gil Novales, El Trienio liberal, Madrid, Siglo XXI, 1980, p. 41-42.

51. Pedro Rújula, Constitución... op.cit., p. 37.

52. La Junta Superior gubernativa de Aragón a sus conciudadanos sobre varias de las ventajas que resultarán a los pueblos de la puntual observancia de la Constitución de la Monarquía, Zaragoza, Imprenta de Francisco Magallón, 1820, p. 5-6.

53. Ibídem, p. 14.

54. Ibídem, p. 15.

55. LACMZ, 14.04.1820, fols. 53-54; 21.04.1820, fol. 64; 28.04.1820, fol. 65; 30.05.1820, fol. 81 y 7.07 .1820 , fols.104 y 106.

56. LACMZ, 4.05.1821, fol. 58; 2.06.1821, fol. 81; y 22.09.1821, fol. 124.

57. LACMZ, 23.02.1821, fols. 30-31.

58. Faustino Casamayor, op.cit., tomo 38, 5 de marzo de 1821, fol. 42-43

59. Ibídem.

60. LACMZ, 28.05.1823, fol. 69 y 28.05.1824. fol. 99. Asimismo, el día 10 de noviembre se realizó un solemne oficio de difuntos por todos los que desde el día 7 de marzo han muerto por la causa de Dios y del Rey. LACMZ, 29.10.1823, fol. 194 y 14.11.1823, fol. 213. 61. LACMZ, 28.05.1823, fol. 71 y 29.08.1823, fol. 137.

62. L.A.C.M.Z., 7.11.1823, fol. 84; 26.04.1823, fol. 52 y Charles-Alexandre Geoffroy de Grandmaison, L'Expédition française d'Espagne en 1823; Avec 11 lettres inédites, París, Plon, 1927, pp. 108-109.

63. Ver Francisco Javier Ramón Solans, La Virgen del Pilar dice..., op.cit., p. 108-128.

64. René de Chateaubriand, Congres de Vérone. Guerre d'Espagne. Négociations. Colonies espagnoles, París, Delloyé, 1838, p. 24

\section{RESÚMENES}

El objetivo de este artículo es analizar las relaciones entre religión y política durante el Trienio liberal (1820-1823) desde una perspectiva local y eclesiástica. Tras un breve repaso historiográfico sobre las relaciones entre religión, ilustración y liberalismo, nos centraremos en las reacciones del Cabildo zaragozano a la instalación del régimen constitucional y cómo contribuyeron a la legitimación de este cambio político. En una segunda parte, abordaremos la actividad conspirativa de la jerarquía eclesiástica zaragozana, su impacto en los medios así como las diversas estrategias para defender su honor ante la opinión pública. Finalmente, veremos cómo a pesar de sus diferencias con las nuevas autoridades, el Cabildo no dudó en participar en los nuevos rituales políticos cuándo fue requerido por las autoridades. Este artículo plantea la hipótesis de que esta colaboración fue vista por el Cabildo como algo natural y que haberse negado a tomar parte hubiera contribuido paradójicamente a la secularización del espacio político 
L'objectif de cet article est d'analyser les relations entre la religion et la politique pendant le Trienio liberal (1820-1823) d'un point de vue local et ecclésiastique. Après un bilan historiographique sur les rapports entre religion, Lumières et libéralisme, nous tâcherons de montrer comment le Chapitre de Saragosse réagit à l'installation du régime constitutionnel et comment il contribua à légitimer ce changement politique. Dans une deuxième partie, nous aborderons l'activité conspiratrice de la hiérarchie ecclésiastique de Saragosse, son impact sur les médias ainsi que les différentes stratégies pour défendre sa réputation devant l'opinion publique. Enfin, nous verrons comment, malgré ses différences avec les nouvelles autorités, le Chapitre n'hésita pas à prendre part aux nouveaux rituels politiques quand il fut sollicité par les autorités. Ces résultats nous amènent à formuler l'hypothèse que cette collaboration était perçue par le Chapitre comme quelque chose de naturel et que refuser d'y participer aurait paradoxalement contribué à la laïcisation de l'espace politique.

This article examines the relationships between religion and politics during the Trienio liberal (1820-1823) from a local and ecclesiastical perspective. After offering a brief historiographical account on the relationships between Religion, Enlightenment and Liberalism, this essay explores the reactions of the cathedral Chapter of Zaragoza to the installation of the constitutional regime and how they contributed to the legitimation of this political change. Secondly, we explore the conspiratorial activity of the ecclesiastical hierarchy of Zaragoza, its impact on the media as well as the strategies they followed to defend its reputation before the public opinion. Finally, in spite of its differences with the new authorities, evidences lead us to conclude that the cathedral Chapter did not hesitate to get involved in the new political rituals when it was required by them. This article raises the hypothesis that this collaboration was seen by the Chapter as something natural and the refusal to take part in it would have contributed paradoxically to the secularization of this political space.

\section{ÍNDICE}

Palabras claves: Iglesia, Clero, Zaragoza, Trienio Liberal

Keywords: Church, clergy, Zaragoza, Liberal triennate

Mots-clés: Église, clergé, Saragosse, Triennat libéral

\section{AUTOR}

\section{FRANCISCO JAVIER RAMÓN SOLANS}

Universidad de Zaragoza 